\title{
Laparoscopy in combination with fast-track management is the best surgical strategy in patients undergoing colorectal resection for cancer
}

\author{
J.-L. Faucheron ${ }^{1} \cdot$ B. Trilling ${ }^{1}$
}

Received: 5 April 2015/Accepted: 14 April 2015/Published online: 21 May 2015

(C) Springer-Verlag Italia Srl 2015

Enhanced recovery after surgery provides patients with optimal means to counteract or minimize the deleterious effects of surgery [1]. This concept can be adapted to suit colorectal procedures and comes in the form of a clinical pathway covering the pre-, intra-, and postoperative periods. In a prospective randomized trial, Vlug et al. [2] concluded that laparoscopy in combination with fast-track multimodal management was a better strategy than laparoscopy in a standard care or open surgery in either fasttrack or standard care. We feel that laparoscopic colorectal resection for cancer in a fast-track surgery setting is probably the best way to treat patients in 2015 , but this is better demonstrated by evidence-based and already published facts than by Vlug and colleagues' [3-5] prospective, randomized, four-arm trial.

A French expert panel assessed the impact of each parameter typically included in the fast-track programs on six foreseeable consequences of colorectal surgery: surgical stress, postoperative ileus, fluid and electrolyte imbalances, decreased postoperative mobility, sleep disorders, and postoperative complications. The experts validated the value of each parameter in terms of efficacy criteria for success of rapid rehabilitation programs. After analysis of the literature, 19 parameters were identified as potentially impacting at least one of the foreseeable consequences of colorectal surgery, namely the rate of postoperative complications and the duration of hospital stay. After synthesis of the work of experts on the 19 parameters using a well-defined

J.-L. Faucheron

JLFaucheron@chu-grenoble.fr

1 Colorectal Unit, Department of Colorectal Surgery, Grenoble University Hospital, CS 10217, 38043 Grenoble Cedex, France methodology, the organizing committee reached 35 formal recommendations that were published as guidelines [6].

Consensus was reached among anesthesiologists, nutritionists, and surgeons on a number of recommendations that should be applied in current rehabilitation programs in colorectal surgery, such as: preoperative immunonutrition; preoperative intake of carbohydrates till $2 \mathrm{~h}$ before operation; no bowel preparation for colon surgery; laparoscopic surgery; antibiotic prophylaxis; prevention of hypothermia; systematic medication to prevent nausea and vomiting; morphine-sparing analgesia techniques; optimization of intraoperative volume control; no gastric tube; no drainage for elective surgery; short-term bladder catheterization; resumption of oral feeding within $24 \mathrm{~h}$; getting the patient out of bed and walking on the first day. Patient information all along the pathway has also been considered as an important point for an enhanced recovery program.

French surgeons and anesthesiologists decided to create a francophone group of experts applying these principles in colorectal surgery and then in all kinds of abdominal operations and met in an association called groupe francophone interdisciplinaire de rehabilitation améliorée en chirurgie (GRACE), which is the equivalent of the enhanced recovery after surgery (ERAS) group English-speaking countries.

Conflict of interest None.

\section{References}

1. Kehlet H, Wilmore DW (2008) Evidence-based surgical care and the evolution of fast-track surgery. Ann Surg 248:189-198 
2. Vlug MS, Wind J, Hollmann MW et al (2011) Laparoscopy in combination with fast track multimodal management is the best perioperative strategy in patients undergoing colonic surgery. A randomized clinical trial (LAFA-study). Ann Surg 254:868-875

3. Faucheron JL (2013) Laparoscopy in combination with fast-track management is probably the best perioperative strategy in patients undergoing colonic resection for cancer. Ann Surg 257:5

4. Lohsiriwat V (2014) The influence of preoperative nutritional status on the outcomes of an enhanced recovery after surgery (ERAS) programme for colorectal cancer surgery. Tech Coloproctol 18:1075-1080
5. Barr J, Boulind C, Foster JD et al (2015) Impact of analgesic modality on stress response following laparoscopic colorectal surgery: a post hoc analysis of a randomised controlled trial. Tech Coloproctol 19:231-239

6. Alfonsi P, Slim K, Chauvin M, Mariani P, Faucheron JL, Fletcher D (2014) French guidelines for enhanced recovery after elective colorectal surgery; Working Group of Société française d'anesthésie et réanimation (SFAR); Société française de chirurgie digestive (SFCD). J Visc Surg 151:65-79 